See discussions, stats, and author profiles for this publication at: https://www.researchgate.net/publication/323621788

\title{
Knowledge Transfer by the Global Terrestrial Network for Permafrost (GTN-P)
}

Chapter · March 2018

DOI: 10.1007/978-3-319-75919-7_11

CITATIONS

0

2 authors:

Boris K Biskaborn

Alfred Wegener Institute Helmholtz Centre for Polar and Marine Research 39 PUBLICATIONS 278 CITATIONS

SEE PROFILE

Some of the authors of this publication are also working on these related projects:

Quantifying carbon, nutrient and sediment fluxes in the Arctic nearshore zone along eroding permafrost coasts View project
Hugues Lantuit

Alfred Wegener Institute Helmholtz Centre for Polar and Marine Research 147 PUBLICATIONS 1,437 CITATIONS

SEE PROFILE

Arctic Environmental Data Analytics View project 


\title{
Knowledge Transfer by the Global Terrestrial Network for Permafrost (GTN-P)
}

\author{
Boris K. Biskaborn and Hugues Lantuit
}

\section{Background}

Permafrost ecosystems occupy a quarter of the land surface in the Northern Hemisphere. Ongoing rapid temperature change in these areas causes permafrost warming in the Arctic and thawing in the Subarctic regions (Romanovsky et al. 2010). Permafrost degradation associated with rising air temperatures are considered to amplify warming of the atmosphere through the conversion of soil organic carbonthat has been frozen for thousands of years, into greenhouse gases (Schuur et al. 2015). The GTN-P scientific community provides assessments of the impacts of warming permafrost to the global climate system. In this way, GTN-P data products are highly relevant for a broad range of stakeholders from scientific, public and economical sectors .

The Global Terrestrial Network for Permafrost (GTN-P, gtnp.org) is part of the Global Climate Observing System (GCOS) and the World Meteorological Organization (WMO). It was established in 1999 by the International Permafrost Association (IPA) aiming for systematic and long-term documentation of the distribution, variability and trends of permafrost. Permafrost has been identified as an Essential Climate Variable (ECV) by GCOS; GTN-P defined permafrost temperature and active layer thickness as main indicators and developed a Data Management System (DMS) for these two variables. Coordinated by AWI and funded by the EU project PAGE21 and ESKP, the GTN-P Database was launched in September 2015. The database currently includes about 1300 permafrost temperature boreholes and 250 active layer sites from the terrestrial Arctic, Antarctic and mountain areas (Figs. 1 and 2).

B. K. Biskaborn $(\square) \cdot$ H. Lantuit

Alfred Wegener Institute Helmholtz Centre for Polar and Marine Research, Telegrafenberg A43, 14473, Potsdam, Germany

e-mail: boris.biskaborn@awi.de

G. Krause (ed.), Building Bridges at the Science-Stakeholder Interface, SpringerBriefs

in Earth System Sciences, https://doi.org/10.1007/978-3-319-75919-7_11 


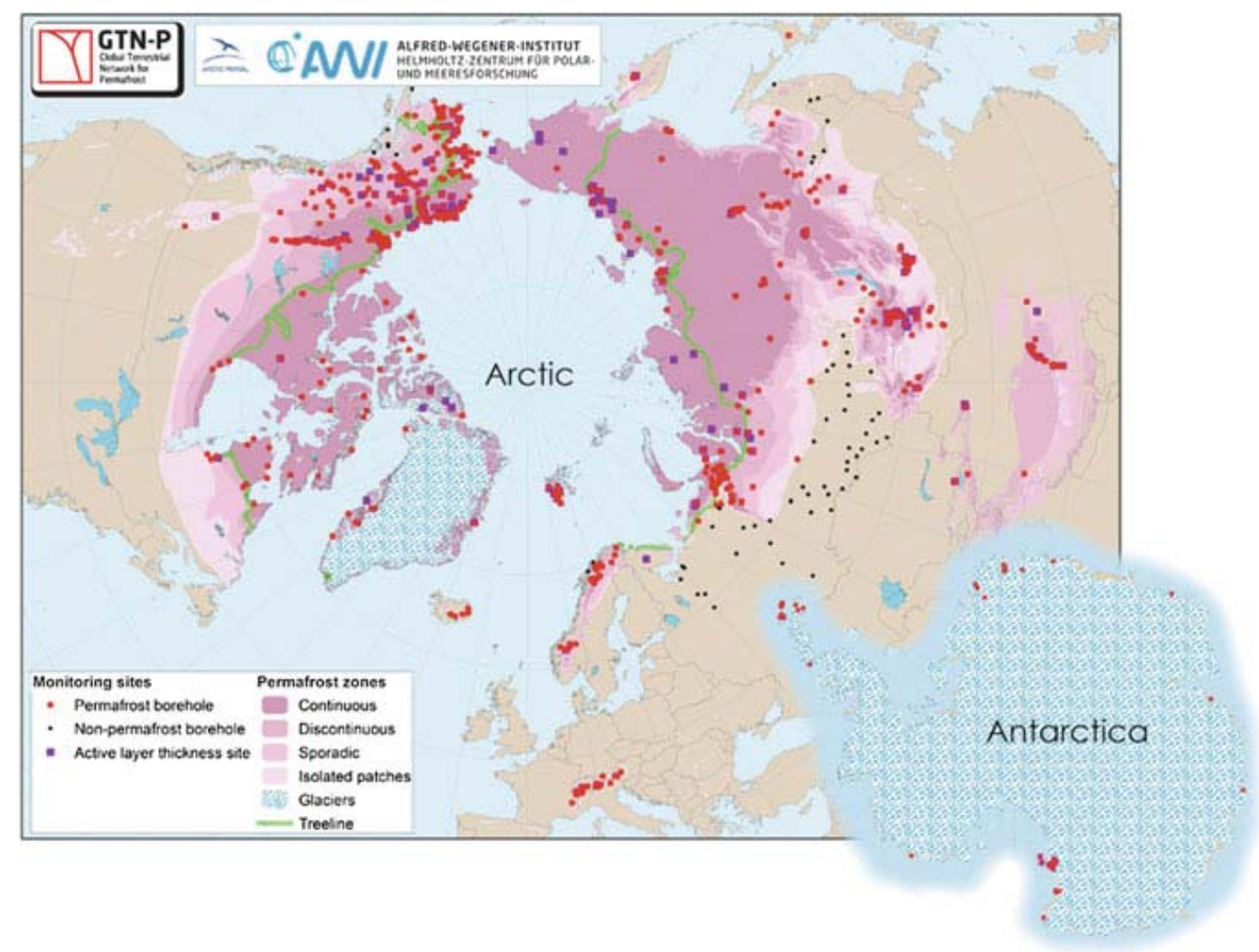

Fig. 1 Distribution of boreholes and active layer thickness sites in the GTN-P Database. Permafrost zones adopted from IPA.

Fig. 2 Two main variables in GTN-P, temperature and active layer thickness, describing the ground thermal regime in permafrost

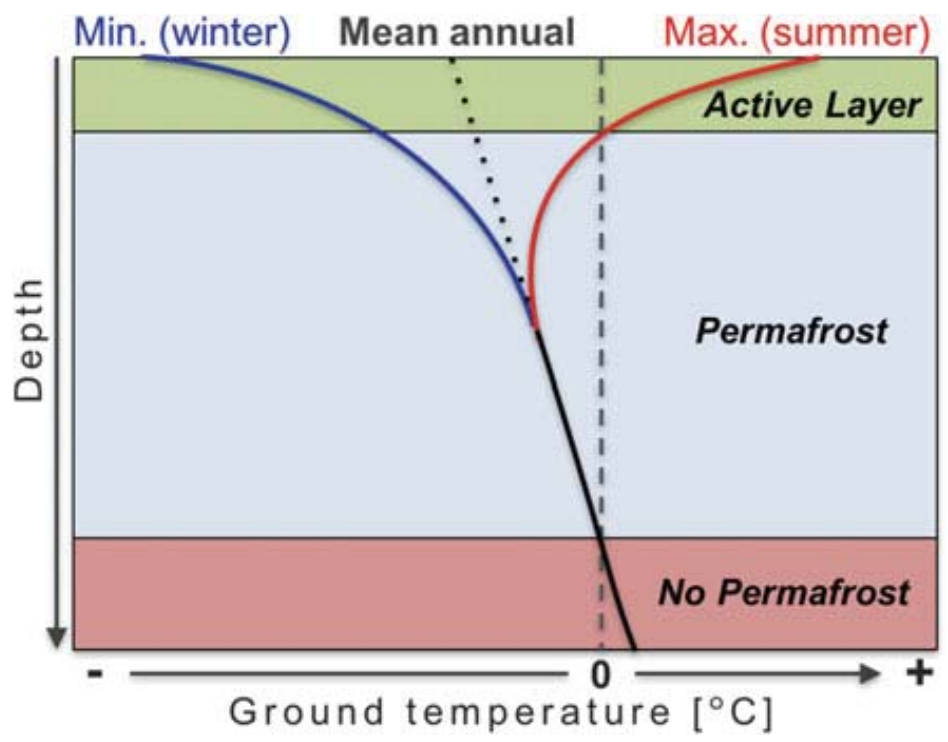




\section{Scope and Motivation}

Over the last decades, the Periglacial Research section in Potsdam established AWI as one of the leading institutes in international permafrost research. With increasing attention on environmental science on hemispheric to global scale, the AWI established international data management that is strongly coupled with knowledge transfer. Via ESKP, AWI developed and organized regular transfers of permafrost science highlights to the public, including political and economic sectors.

Co-hosted by the Arctic Portal (http://arcticportal.org/) and the Alfred Wegener Institute, the GTN-P Database and its data management systemprovide a critical link between the researchers involved in field data collection and a variety of end-users, from expert climate modelers, to policy makers, to the general public interested in aspects related to permafrost. Main stakeholders are scientists, public audience, universities, schools and environmental agencies. For this purpose, the DMS was developed with an easy-to-use interface, with extraordinary capacities in automated data visualization, based on user requirement questionnaires and various test phases.

\section{Materials and Methods}

The GTN-P Database (GTN-P 2015, Biskaborn et al. 2015) was developed in close collaboration between the AWI and the Arctic Portal(http://arcticportal.org/) and is accessible online at http://gtnpdatabase.orgor through the GTN-P website at http:// gtnp.org. The general framework of the GTN-P Database is based on open source technologies following an object-oriented data model (Fig. 3) implemented with CakePHP and the spatial version of PostgreSQL. The database structure distinguishes between permafrost temperatures and annual thaw depths. The DMS is constantly improving, allowing for user-friendly data submission, processing and standardization of field data, and the provision of necessary tools for data-queries, visualization, and the ability to download data in various formats. To ensure interoperability and enable inter-database search, metadata field names are based on a controlled vocabulary registry (gtnp.org, ISSN 2410-2385). GTN-P follows an open-access policy in line with the IPY (International Polar Year) data policy and the GEO (Group on Earth Observations) data sharing principles.

Knowledge transfer from the AWI Periglacial Research Section, feeding in the ESKP Permafrost topic, is coordinated by an AWI scientist following (a) proactive and (b) reactive strategies. Proactive: transfer of main relevant outcomes of high-impact papers or expeditions from the section. Reactive: transfer of knowledge as reaction to geo-events that receive attention in the news, e.g. the crater holes in the Arctic (http://www.eskp.de/warnung-vor-weiteren-kratern-in-sibirien/). 


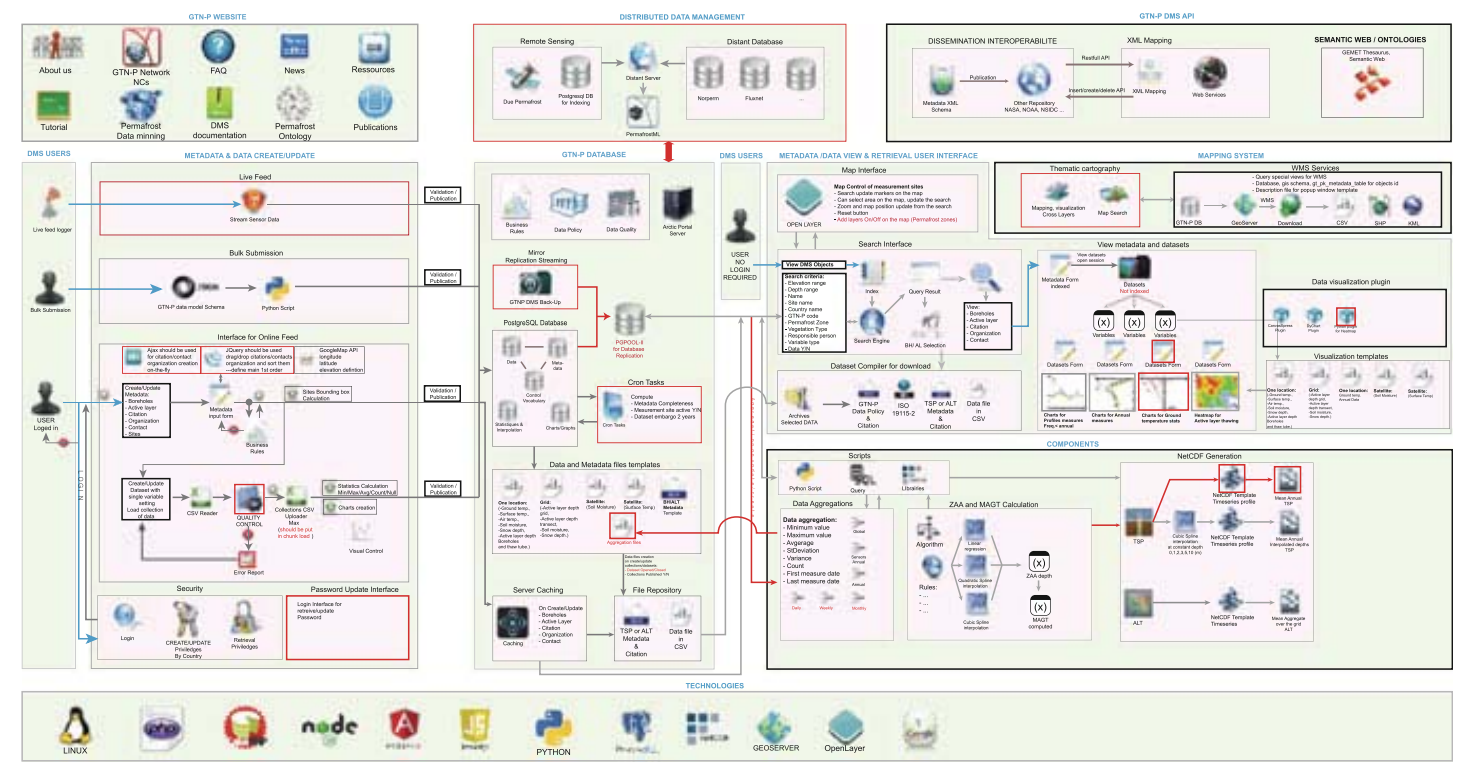

Fig. 3 Object oriented model of the GTN-P data management system

GTN-P Database products are freely available in harmonized formats (CSV, XML, KML, GIS shapefiles) as well as in network Common Data Form (NetCDF) to facilitate implementation in global models.

\section{Results}

Within the period funded by ESKP, the 2nd GTN-P National Correspondents Workshop, supported by AWI,IASC (International Arctic Science Committee) and IPA (International Permafrost Association), took place in Quebec, Canada. It was visited by 30 participants representing 16 countries, involved either in the GTN-P Steering Committee, the Secretariat, Advisory Board, as National Correspondent or as invited external collaborator (e.g. IASC, IPA, NSIDC (the National Snow and Ice Data Center) and NORDICANA-D). During the workshop the new database governance structure and terms of reference were approved. Several keynote talks were given on GTN-P in the modern scientific society. National Correspondents (NC) gave short talks on the state and availability of boreholes and active layer sites in their countries, and the needs to facilitate data management for data flow toward GTN-P were identified. The Permafrost Young Research Network (PYRN) was involved to establish "Young National Correspondents" of GTN-P, who actively support data management and participate in scientific reports, meetings, workshops and publications. GTN-P Database and metadata statistics were published in the journal ESSD (Biskaborn et al. 2015). The policy for the report on permafrost temperature development was also planned during this workshop. It was decided to establish a mirror of the GTN-P database at research institutes, e.g. in Russia, to facilitate data transfer on a national level. The next major GTN-P meeting was 
organized by AWI right before the ICOP2016 in Potsdam and brought together 50 participants from 20 countries. The participants discussed specifically the contribution of the GTN-P community to the GCOS Implementation Plan, and the development of a GTN-P Strategy and Implementation Plan 2020 (Streletskiy et al. 2017), a document that outlines network milestones and priorities for the next four years. The conference session "Results from GTN-P: TSP, CALM, and related environmental datasets and models" was the largest at the conference (with 60 abstracts), highlighting the important role of GTN-P within the international permafrost community.

In 2014, six articles on permafrost research highlights were published on the ESKP website, and since then the project output for ESKP is in average five articles per year (17 articles in August 2017 in total). Three ESKP articles described the development and the products of the GTN-P Database. At the moment, the main publication of the global thermal development of permafrost is in preparation and has already been shown on international conferences. The main product is conceived as a map showing the temperature differences (anomalies) of the last 10 years in the Arctic, the Antarctic and Mountain permafrost.

\section{Reflection and Lessons Learned}

As shown by ranking in clicks on ESKP articles, the topic permafrost receives exceptional attention from the ESKP readership. Since development of GTN-P data visualization, funded by ESKP, requests from public, scientific stakeholders and journalists to GTN-P Database products such as maps and datasets on permafrost temperature and active layer thickness increased significantly.

Knowledge transfer is facilitated by outreach activities based on data visualization provided in quality- proven graphics and maps.

\section{Outlook}

GTN-P is preparing the first report on global permafrost temperature change (Fig. 4). The report will be transferred to an ESKP article in both German and English. The dataset will be provided in standardized and quality-checked format to the modeling community. GTN-P is drafting the new GTN-P Strategy and Implementation Plan (2016-2020), including a funding concept to involve stationary data on climate observation, and to establish additional mirrors of the database at selected research institutes, e.g. in Germany and in Russia for facilitating data management and data input on national level. 


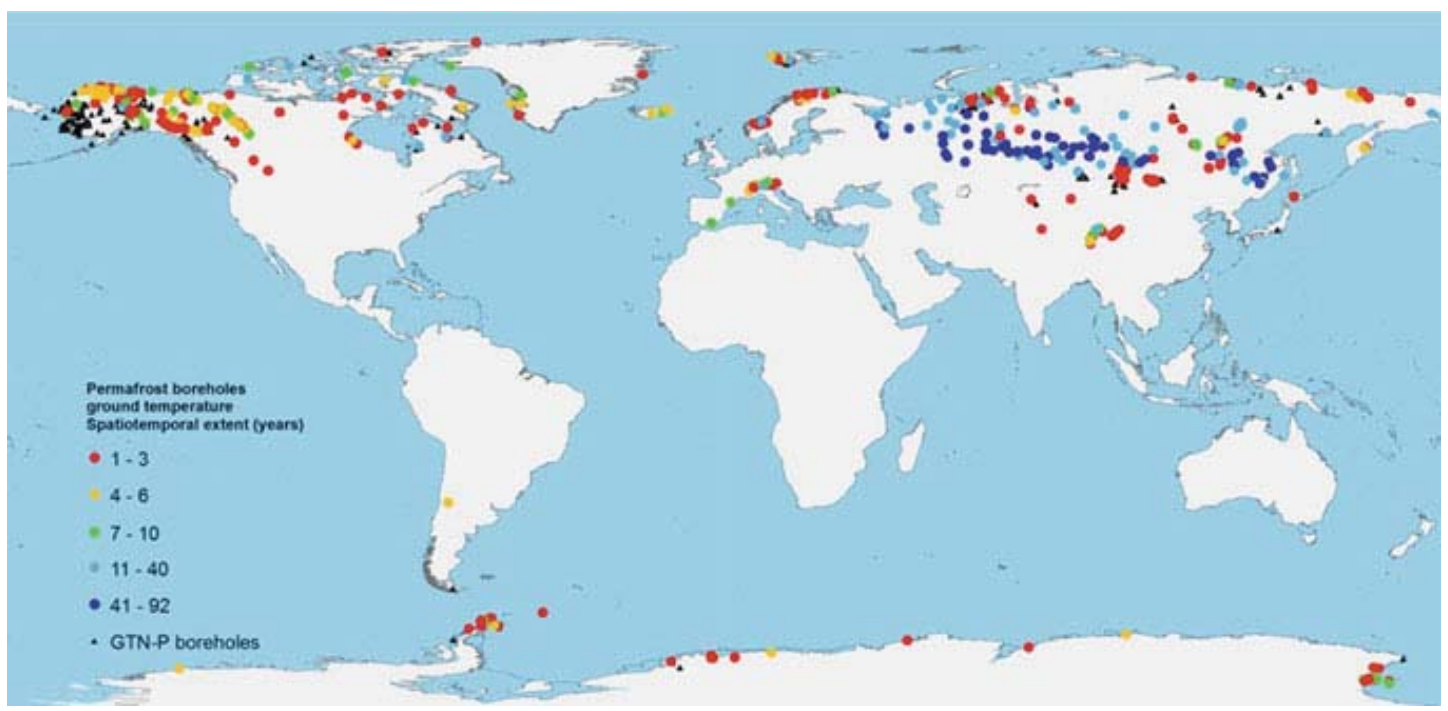

Fig. 4 Visualization of the temporal extend of data sets with mean annual ground temperature values in the GTN-P Database. This data set is currently being quality-checked and processed to report on the global temperature change in permafrost

Acknowledgements We thank ESKP for providing one year financial support to develop the visualization products of GTN-P Database. We thank Karl Dzuba for assisting with proof-reading the ESKP articles on permafrost research highlights. We also thank Jean-Pierre Lanckman, Malek Kaderi and Anseok Joo (Arctic Portal), and Almut Dressler and Saskia Bacher (AWI) for data management.

\section{References}

Biskaborn, B. K., Lanckman, J. P., Lantuit, H., Elger, K., Streletskiy, D. A., Cable, W. L., et al. (2015). The new database of the Global Terrestrial Network for Permafrost (GTN-P). Earth System Science Data, 7, 245-259.

GTN-P (2015). GTN-P metadata for permafrost boreholes (TSP) and active layer monitoring (CALM) sites. Journal Volume, Pages. http://dx.doi.org/10.1594/PANGAEA.842821.

Romanovsky, V. E., Smith, S. L., \& Christiansen, H. H. (2010). Permafrost thermal state in the polar northern hemisphere during the international polar year 2007-2009: A synthesis. Permafrost and Periglacial Processes, 21, 106-116. https://doi.org/10.1002/ppp.689.

Schuur, E. A. G., McGuire, A. D., Schadel, C., Grosse, G., Harden, J. W., Hayes, D. J., et al. (2015). Climate change and the permafrost carbon feedback. Nature, 520, 171-179.

Streletskiy, D., Biskaborn, B., Smith, S., Noetzli, J, Viera, G., Schoeneich, P. (2017). GTN-P-Strategy and Implementation Plan 2016-2020. In: Strategy and Implementation Plan 2016-2020 for the Global Terrestrial Network for Permafrost (GTN-P) (42pp). Washington D.C.: The George Washington University. 